\title{
In vitro evaluation of antimicrobial activity of Distemonanthus benthamianus chewing stick extract mouthwash
}

\author{
Mbang Nyong Femi-Oyewo ${ }^{1}$ (D), Olutayo Ademola Adeleye ${ }^{1}$ (D) Caroline Olufunke Babalola ${ }^{1}$ (D), \\ Olufemi Babatunde Banjo ${ }^{1}$ (D, Modupe Nofisat Adebowale ${ }^{2}$ (D), Florence Olubola Odeleye ${ }^{3}$ (i) \\ 'Olabisi Onabanjo University, Department of Pharmaceutics and Pharmaceutical Technology, Ago -Iwoye, Ogun State, Nigeria \\ ${ }^{2}$ Olabisi Onabanjo University, Department of Pharmacognosy, Ago Iwoye, Ogun State, Nigeria \\ ${ }^{3}$ Olabisi Onabanjo University, Department of Pharmaceutical Microbiology, Ago Iwoye, Ogun State, Nigeria
}

ORCID IDs of the authors: M.N.F. 0000-0003-0025-2227; 0.A.A. 0000-0001-8716-4064; C.0.B. 0000-0002-1742-8762; 0.B.B. 0000-0002-6970-516X; M.N.A. 0000-0002-0944-0702; F.0.0. 0000-0002-1783-1463

Cite this article as: Femi-Oyewo, M. N., Adeleye, O. A., Babalola, C. O., Banjo, O. B., Adebowale, M. N., \& Odeleye, F. 0. (2021). In vitro evaluation of antimicrobial activity of Distemonanthus benthamianus chewing stick extract mouthwash. Istanbul Journal of Pharmacy, 51(1), 105-110.

\begin{abstract}
Background and Aims: Mouthwashes are oral home care product used to treat mouth infections and to maintain satisfactory oral hygiene. The use of effective mouthwash is a reasonable means to prevent dental caries and oro-dental infections. The aim of this study was to evaluate the antimicrobial potential of Distemonanthus benthamianus chewing stick extract formulated as a mouthwash against some microorganisms associated with oro-dental infections in comparison with two commercial brand mouthwashes.

Methods: The chewing stick was extracted with methanol and used to formulate mouthwash. Phytochemical screening was done to test for the presence of secondary metabolites. Antimicrobial activity of the crude extract and the formulated mouthwash on Staphylococcus aureus, Streptococcus mutans and Candida albicans was evaluated. The physical characteristics, $\mathrm{pH}$ and the stability of the mouthwashes were determined.

Results: The extract contains alkaloids, saponins flavonoids, steroids and tannins. The crude extract and the formulated mouthwashes showed significant difference in activity against the test microorganisms in the following order Candida albicans $>$ Staphylococcus aureus $>$ Streptococcus mutans. At high concentrations of the extract $(0.3 \% \mathrm{~W} / \mathrm{V}$ and $0.5 \% \mathrm{~W} / \mathrm{V})$ in formulations, antibacterial activities were significantly higher against Streptococcus mutans and Staphylococcus aureus when compared with the commercial brands. The $\mathrm{pH}$ of the mouthwashes ranged from $5.2-7.4$. The stability of formulation F5 was maintained for 12 weeks.

Conclusion: The use of Distemonanthus benthamianus chewing stick extract mouthwash is safer, cheaper, and more effective in preventing dental caries and oro-dental infections compared to the commercial brand mouthwashes.
\end{abstract}

Keywords: Antimicrobial activity, chewing stick, microorganisms, mouthwash 


\section{INTRODUCTION}

Mouthwashes are oral home care products. They are clear nonsterile aqueous solution termed medicated liquid intended to deodorize, clean and treat mouth infections. They are used to treat mouth infections and to ensure or maintain satisfactory oral hygiene to enhance oral health (Khirtika, Ramesh, \& Muralidharan, 2017). Thus, the use of effective mouthwash is a reasonable means to prevent dental caries and oro-dental infections. This is achieved by the presence of chemical antimicrobial agents such as cetylpyridinium chloride, triclosan or chlorhexidine and essential oils in many of the commercially available mouthwash brands (Masadeh, Gharaibeh, Alzoubi, Al-Azzam, \& Obeidat, 2013; Dabholkar, Shah, Kathariya, Bajaj, \& Doshi, 2016; Kunte, Kadam, Patel, Shah, Lodaya, \& Lakde, 2018).

The use of chewing sticks have been encouraged by the WHO since 1987 due to their enormous oral health benefits such as the elimination of bad odour, good cleansing properties and wide spectrum antimicrobial activities which they possess in the general maintenance of oral hygiene (Malik, Shaukat, Qureshi, \& Abdur, 2014). They are less toxic because of their natural source. They are abundant in nature which makes them readily available and cheap. For people of low economic stature, they are a cheaper and safer alternative of mouth cleansing to commercial mouthwashes with side effects such as tooth staining and vomiting (Yadav \& Yadav, 2013; Parkar, Thakkar, \& Shah, 2013).

Distemonanthus benthamianus Baill. is a semi-deciduous tree which belongs to the family Leguminosae. It is commonly known as African satinwood in English and as movingui in French. It is widespread in Ghana and Nigeria, and known as "bonsamdua" and "ayan", respectively (Adeniyi, Obasi, \& Lawal, 2011; Asamoah, Frimpong-Mensah, \& Antwi-Boasiako, 2014). It is used traditionally in the treatment of different skin conditions, rheumatism, pains, fever, uro-genital and gastrointestinal infections (Saha et al., 2014; Shittu, Aliyu, David, Njinga, \& Ishaq, 2019). The root is used in Western Nigeria as a chewing stick for oro-dental hygiene. There are experimental evidences which show that $D$. benthamianus possesses teeth cleansing properties and antimicrobial activity against a wide range of microorganisms associated with dental caries and oro-dental infections such as Streptococcus mutans, Staphylococcus aureus, Candida albicans etc. (Adeniyi \& Odumosu, 2012; Aworinde, Erinoso, \& IbukunOluwa, 2016; Mebude, Adeniyi, \& Lawal, 2017; Shittu et al., 2019). In view of these assertions, this study was carried out to investigate the antimicrobial potentials of the methanol extract of $D$. benthamianus chewing sticks against microorganisms associated with oro-dental infections and also to formulate and evaluate the antimicrobial activity of mouthwash containing different concentrations of the extract in comparison with two commercial brand mouthwashes.

\section{MATERIALS AND METHODS}

\section{Plant collection}

$D$. benthamianus chewing sticks (freshly uprooted root of the plant) were bought same day from Oke-Aje, ljebu Ode, Ogun state, Nigeria in August 2019 and identified at the Forest Research Institute of Nigeria (FRIN) Ibadan, Oyo State by Mr. Sam- uel Odewo. The plant was air dried, cut into pieces and ground into powder using an electric blender.

\section{Test microorganisms}

The test microorganisms used in this study were clinical isolates of S. aureus, S. mutans and C. albicans collected from the Microbiology Department of Olabisi Onabanjo University Teaching Hospital, Sagamu, Ogun State.

\section{Preparation of plant extract}

Five hundred grams of the powdered chewing sticks were extracted by the method of Adeleye, Babalola, Femi-Oyewo, \& Balogun, (2019) with $75 \%$ methanol for 72 hours at room temperature. It was filtered; the filtrate was concentrated with a rotary evaporator at $40^{\circ} \mathrm{C}$ and stored in a refrigerator at $4^{\circ} \mathrm{C}$.

\section{Phytochemical analysis of extract}

The extract was screened for the presence of phytochemicals according to the methods of Trease \& Evans, (1989).

\section{Antimicrobial sensitivity screening}

The antimicrobial sensitivity of the test microorganism to different concentrations of $D$. benthamianus extract prepared with distilled water was evaluated by the agar well diffusion method (Hood, Wilkinson, \& Cavanagh, 2003). The bacterial test isolates were inoculated into Nutrient Broth and incubated for 24 hours at $37^{\circ} \mathrm{C}$ while the fungal test isolate was inoculated into Sabouraud Dextrose Broth and incubated for 48 hours at $37^{\circ} \mathrm{C}$. The inoculated broths were standardized to $0.5 \mathrm{McF}$ arland standards (Hood et al., 2003). A 6 mm cork borer was used to bore wells in an agar plate inoculated with microorganisms (Nutrient Agar for bacterial and Sabouraud Dextrose Agar for fungi) and filled with $0.5 \mathrm{~mL}$ of different concentrations of the extracts, gentamicin or ketoconazole (positive control) and distilled water (negative control). The plates were incubated at $37 \pm 2^{\circ} \mathrm{C}$ for 24 hours and 48 hours for Nutrient Agar Sabouraud Dextrose Agar respectively. Zones of inhibition were measured in millimeters $(\mathrm{mm})$.

\section{Preparation of Distemonanthus benthamianus mouth- wash}

Each formulation (F1 - F5) was prepared according to Table 3. Sodium bicarbonate was dissolved in water and added to the mixture of chloroform water, peppermint oil and propylene glycol in a calibrated bottle. The extract $D$. benthamianus was dissolved in water and strained through a whatman paper to remove particles before being added to the mixture in the bottle.

\section{Evaluation of mouthwash}

Evaluation of physical characteristics of the mouthwashes Physical characteristics (appearance, colour, taste, odour and flavour) of the mouthwashes were determined by visual inspection and sensory evaluation.

\section{Evaluation of $\mathrm{pH}$ of the mouthwashes}

The $\mathrm{pH}$ of the mouthwashes was determined in triplicate using a $\mathrm{pH}$ meter.

\section{Antimicrobial assay of the mouthwashes}

The antimicrobial assay of the mouthwashes was performed by the agar diffusion method similar to the previous method used for antimicrobial sensitivity screening. 
Femi-Oyewo et al. In vitro evaluation of antimicrobial activity of Distemonanthus benthamianus chewing stick extract mouthwash

\section{Panelist perception}

The physical characteristics of the mouthwashes were characterized by subjective physical and sensory assessment by 70 panelists, 10 for each formulation. The panelists were instructed to rate the appearance, taste, flavour, colour, smoothness and acceptability of the mouthwash as they perceived them on two scales of either good or bad and accepted or rejected.

\section{Stability studies of the mouthwash}

The stability of formulation F5 was evaluated by taking samples at specific intervals from the product stored at $4 \pm 1^{\circ} \mathrm{C}, 25 \pm 1^{\circ} \mathrm{C}$ and $50 \pm 1^{\circ} \mathrm{C}$ for 12 weeks (Almekhlafi, Thabit, Alwossabi, Awadth, Thabe, \& Algaadari, 2014; Adeleye et al., 2019). The physical characteristics (appearance, colour, taste, odour and flavour) and antimicrobial properties of the samples were analyzed.

\section{Statistical analysis}

Significant difference in data obtained was analyzed with GraphPad Prism 5.01 using t-test and one-way ANOVA. P-values less than 0.05 were considered statistically significant.

\section{RESULTS}

The phytochemical constituents of the extract are shown in Table 1. The extract contains low concentrations of alkaloids and saponins with moderate concentrations of flavonoids, steroids and tannin.

\section{Table 1. Phytochemicals of Distemonanthus benthamianus extract.}

\begin{tabular}{|lc|}
\hline Test & Result \\
\hline Alkaloids & + \\
Flavonoids & ++ \\
Saponins & + \\
Tannins & ++ \\
Steroids & ++ \\
\hline+ = Low concentration; $++=$ Moderate concentration
\end{tabular}

The antimicrobial assay of different concentrations of the crude extract is presented in Table 2. The crude extract showed a significant difference in activity against the test microorganism with the highest activity at $250 \mathrm{mg} / \mathrm{mL}$ concentration on C. albicans $(27.1 \pm 0.20 \mathrm{~mm})$ followed by S. aureus $(22.5 \pm 0.10 \mathrm{~mm})$ and S. mutans $(16.3 \pm 0.22 \mathrm{~mm})$. The positive control 1 (gentamicin) had activities on S. aureus $(28.5 \pm 0.10 \mathrm{~mm})$ and S. mutans $(25.2 \pm 0.02 \mathrm{~mm})$, and the positive control 2 (ketoconazole) had activity on C. albicans $(22.8 \pm 0.06 \mathrm{~mm})$ while the negative control (distilled water) showed no activity against the test microorganisms.

The composition of the formulated mouthwashes is shown in Table 3, and the physical characteristics and the $\mathrm{pH}$ of the mouthwashes are presented in Table 4. All the mouthwashes are clear solutions in appearance with a minty flavour and with colours ranging from light red to light blue. The formulated mouth-

\section{Table 2. Antimicrobial assay of Distemonanthus benthamianus extract.}

Zone of Inhibition ( $\mathrm{mm}$ )

\begin{tabular}{|c|c|c|c|}
\hline $\begin{array}{l}\text { Extract } \\
(\mathrm{mg} / \mathrm{ml})\end{array}$ & $\begin{array}{l}\text { Streptococcus } \\
\text { mutans }\end{array}$ & $\begin{array}{c}\text { Staphylococcus } \\
\text { aureus }\end{array}$ & $\begin{array}{l}\text { Candida } \\
\text { albicans }\end{array}$ \\
\hline 250 & $16.3 \pm 0.22$ & $22.5 \pm 0.10$ & $27.1 \pm 0.20$ \\
\hline 125 & $14.9 \pm 0.14$ & $20.8 \pm 0.20$ & $24.7 \pm 0.07$ \\
\hline 62.5 & $12.7 \pm 0.06$ & $18.1 \pm 0.04$ & $22.3 \pm 0.16$ \\
\hline 31.25 & $10.1 \pm 0.21$ & $16.0 \pm 0.21$ & $17.8 \pm 0.10$ \\
\hline 15.625 & $8.4 \pm 0.10$ & $12.8 \pm 0.14$ & $12.0 \pm 0.42$ \\
\hline $\begin{array}{l}\text { Positive } \\
\text { control } 1\end{array}$ & $25.2 \pm 0.02$ & $28.5 \pm 0.10$ & - \\
\hline $\begin{array}{l}\text { Positive } \\
\text { control } 2\end{array}$ & - & - & $22.8 \pm 0.06$ \\
\hline $\begin{array}{l}\text { Negative } \\
\text { control }\end{array}$ & - & - & - \\
\hline
\end{tabular}

Positive control 1 = Gentamicin, Positive control 2 = Ketoconazole, Negative control $=$ Distilled water

\section{Table 3. Composition of Distemonanthus benthamianus extracts mouthwash.}

\begin{tabular}{|lccccc|}
\hline Ingredients & F1 & F2 & F3 & F4 & F5 \\
\hline $\begin{array}{l}\text { D. benthamia- } \\
\text { nus extract (g) }\end{array}$ & - & 0.1 & 0.2 & 0.3 & 0.5 \\
$\begin{array}{l}\text { Sodium bicar- } \\
\text { bonate (g) }\end{array}$ & 1.0 & 1.0 & 1.0 & 1.0 & 1.0 \\
$\begin{array}{l}\text { Propylene } \\
\text { glycol (mL) }\end{array}$ & 1.0 & 1.0 & 1.0 & 1.0 & 1.0 \\
$\begin{array}{l}\text { Peppermint oil } \\
\text { (mL) }\end{array}$ & 1.5 & 1.5 & 1.5 & 1.5 & 1.5 \\
$\begin{array}{l}\text { Chloroform } \\
\text { water (mL) }\end{array}$ & 5.0 & 5.0 & 5.0 & 5.0 & 5.0 \\
$\begin{array}{l}\text { Amaranth } \\
\text { solution (mL) }\end{array}$ & 5.0 & 5.0 & 5.0 & 5.0 & 5.0 \\
Water to (mL) & 100.0 & 100.0 & 100.0 & 100.0 & 100.0
\end{tabular}

washes are odourless and neutral in taste while the commercial brand mouthwashes have a pleasant odour and a sweet taste. The $\mathrm{pH}$ of the mouthwashes ranges from 5.2 to 7.4 .

The antimicrobial assay of the mouthwashes is presented in Table 5. All the test microorganisms are susceptible to the mouthwashes but at significantly different degrees except F1 which showed zero activity. Formulation F5 had the highest activity against all the test microorganisms with C. albicans showing the highest susceptibility $(24.6 \pm 0.08 \mathrm{~mm})$, followed by S. aureus $(17.8 \pm 0.20 \mathrm{~mm})$ then S. mutans $(10.5 \pm 0.12 \mathrm{~mm})$.

The physical characterization and sensory assessment of the mouthwashes by panelists indicates that commercial brands generally had better physical and sensory characteristics, and were better accepted than the formulated mouthwashes (Table 6). 
Table 4. Physical characteristics and pH.

\begin{tabular}{|c|c|c|c|c|c|c|c|}
\hline Characteristics & $\mathrm{F} 1$ & F2 & F3 & F4 & F5 & F6 & F7 \\
\hline Appearance & $\begin{array}{l}\text { Clear } \\
\text { solution }\end{array}$ & $\begin{array}{l}\text { Clear } \\
\text { solution }\end{array}$ & $\begin{array}{l}\text { Clear } \\
\text { solution }\end{array}$ & $\begin{array}{l}\text { Clear } \\
\text { solution }\end{array}$ & $\begin{array}{l}\text { Clear } \\
\text { solution }\end{array}$ & $\begin{array}{l}\text { Clear } \\
\text { solution }\end{array}$ & $\begin{array}{l}\text { Clear } \\
\text { solution }\end{array}$ \\
\hline Colour & Light red & Light red & Light red & Light red & Light red & Light blue & Light blue \\
\hline Odour & Odourless & Odourless & Odourless & Odourless & Odourless & pleasant & pleasant \\
\hline Taste & Neutral & Neutral & Neutral & Neutral & Neutral & Sweet & Sweet \\
\hline Flavour & Minty & Minty & Minty & Minty & Minty & Minty & Minty \\
\hline $\mathrm{pH}$ & 7.4 & 7.2 & 7.1 & 6.8 & 6.6 & 6.8 & 5.2 \\
\hline
\end{tabular}

$\mathrm{F} 1=$ mouthwash without herbal extract, F2 - F5 = formulated mouthwash containing $0.1 \%, 0.2 \%, 0.3 \%$, and $0.5 \%$ Distemonanthus benthamianus extract respectively, F6 \& F7 = commercial brand mouthwash; F6 mouthwash composition = triclosan sorbitol, alcohol, sodium saccharin, sodium lauryl sulfate, polyvinyl methyl ether/maleic acid copolymer, flavouring agents; F7 mouthwash composition = thymol, eucalyptol, methyl salicylate, menthol, sodium benzoate, benzoic acid, sorbitol, ethanol.

Table 5. Antimicrobial assay of mouthwashes.

\begin{tabular}{|lcccccccc|}
\hline \multicolumn{7}{c|}{ Zone of Inhibition (mm) } \\
\hline Microorganisms & F1 & F2 & F3 & F4 & F5 & F6 & F7 \\
\hline Streptococcus mutans & - & $5.2 \pm 0.02$ & $6.6 \pm 0.10$ & $8.3 \pm 0.03$ & $10.5 \pm 0.12$ & $9.5 \pm 0.04$ & $6.3 \pm 0.04$ \\
Staphylococcus aureus & - & $9.2 \pm 0.24$ & $13.5 \pm 0.06$ & $15.1 \pm 0.21$ & $17.8 \pm 0.20$ & $16.2 \pm 0.05$ & $14.7 \pm 0.10$ \\
Candida albicans & - & $15.5 \pm 0.15$ & $18.2 \pm 0.20$ & $20.7 \pm 0.24$ & $24.6 \pm 0.08$ & $14.3 \pm 0.21$ & $11.7 \pm 0.02$ \\
\hline
\end{tabular}

\section{Table 6. Panelist rating of physical characteristics.}

\begin{tabular}{|lccccccc|}
$\begin{array}{l}\text { Character- } \\
\text { istics }\end{array}$ & F1 & F2 & F3 & F4 & F5 & F6 & F7 \\
\hline Appearance & 80 & 70 & 80 & 70 & 70 & 80 & 80 \\
Colour & 80 & 80 & 80 & 60 & 80 & 80 & 80 \\
Odour & 60 & 60 & 60 & 50 & 50 & 90 & 80 \\
Flavour & 50 & 40 & 40 & 50 & 40 & 100 & 80 \\
Taste & 40 & 30 & 40 & 40 & 30 & 100 & 80 \\
Smoothness & 100 & 80 & 80 & 80 & 60 & 100 & 100 \\
Acceptability & 50 & 40 & 40 & 50 & 40 & 100 & 80 \\
\hline
\end{tabular}

Figures 1,2 and 3 show the antimicrobial stability of formulation F5 for 12 weeks. The stability was maintained at all experimental temperatures for 12 weeks.

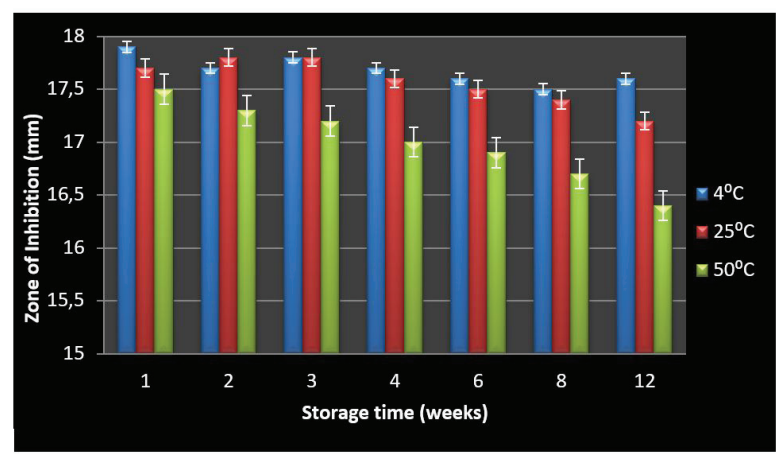

Figure 1. Antimicrobial stability of F5 mouthwash on Staphylococcus aureus over time.

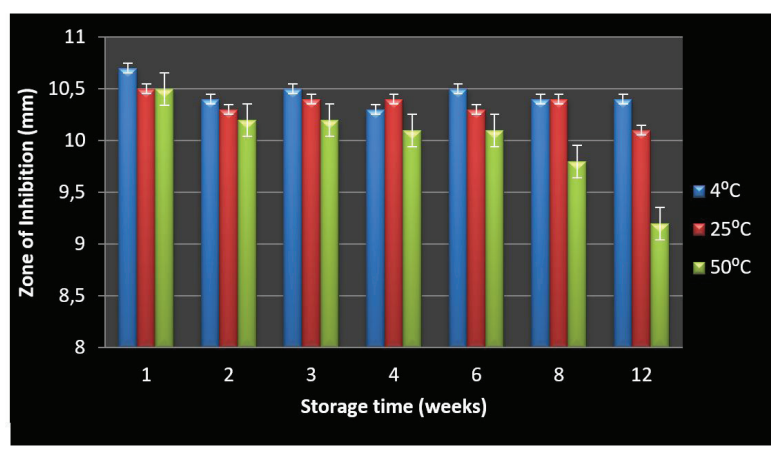

Figure 2. Antimicrobial stability of F5 mouthwash on Streptococcus mutans over time.

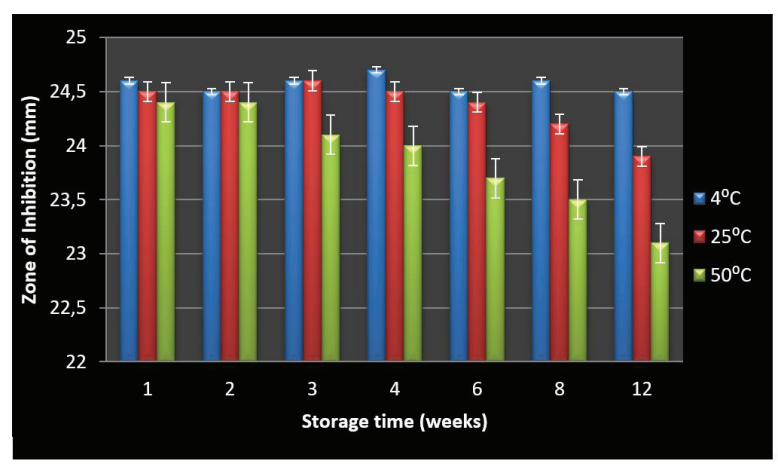

Figure 3. Antimicrobial stability of F5 mouthwash on Candida albicans over time. 


\section{DISCUSSION}

A phytochemical test was performed to find the phytochemical constituents (bioactive secondary metabolites) present in $D$. benthamianus extract. Table 1 shows that the extract contains alkaloids, steroids, flavonoids, saponins and tannins as highlighted by other researchers (Aiyegoro, Akinpelu, Afolayan, \& Okoh, 2008; Shittu et al., 2019; Obiang, Misso, Atome, Ondo, Engonga, \& Emvo, 2019). The presence of some of these compounds has been linked to the antimicrobial activity of the extract. Adeniyi, Adeonipekun, \& Omotayo, (2014); Aworinde et al., (2016); Mebude et al., (2017), reported that the presence of tannins, alkaloids, flavonoids and steroids in plants are responsible for their antimicrobial activities.

The antimicrobial assay of the crude extract revealed activity against the three test microorganisms and the susceptibility of the microorganisms to the extract was in the following order: C. albicans $>$ S. aureus $>$ S. mutans. The antimicrobial activity increased significantly $(P<0.05)$ as the concentration of the extract increased. This indicates that the activity of the extract is concentration-dependent. As discussed above, the presence of tannins, alkaloids, flavonoids and steroids in the extract could be the reason for the antimicrobial activity of the extract. Physical characteristics (appearance, colour, odour, taste and flavor) of the formulated mouthwashes (F1-F5) and the commercial brand mouthwashes (F6-F7) showed that the formulations are clear solutions without particulate matters. The light red colouration and the minty flavour of the formulated mouthwashes were due to the inclusion of amaranth solution and peppermint oil respectively in the composition of the mouthwash. F1-F5 are odourless and neutral in taste but the commercial brands are pleasant in odour with a sweet taste.

The ideal $\mathrm{pH}$ range of saliva is 6.2-7.6 with an average $\mathrm{pH}$ of 6.7 (Baliga, Muglikar, \& Kale, 2013), which helps maintain the $\mathrm{pH}$ of the mouth, including keeping the $\mathrm{pH}$ of the gum and teeth within a range of 6.7-7.3 so as to prevent proliferation of cariogenic bacteria, tooth demineralization, tooth decay and gum diseases (Zhao, Tsoi, Wong, Chu, \& Matinlinna, 2017). When the mouth $\mathrm{pH}$ falls below the critical $\mathrm{pH}$ value of 5.5, various oral health complications could arise. As a result of low oral $\mathrm{pH}$, incidences of tooth decay, enamel erosion, cariogenic bacterial growth, dental caries etc. have been reported (Takahashi, 2005; Van Zyk, \& Van Heerdem, 2010; Belardinelli, Morelatto, Benavidez, Baruzzi, \& López de Blanc, 2014; Dave, Gurunathan, \& Vasantharajan, 2018). For pH compatibility with saliva, formulations should be within the mouth pH range (Baliga et al., 2013). The $\mathrm{pH}$ of the mouthwashes in this study ranged from 5.2-7.4. Only F7 fell below the $\mathrm{pH}$ range of the mouth, which could reduce saliva $\mathrm{pH}$ below the critical value. The implication is that if used over a long period of time it could further aggravate incidences of oro-dental infections. So, it is important to ensure that mouthwashes are buffered to be in the alkaline region to maintain the optimum saliva $\mathrm{pH}$.

The three test microorganisms were susceptible to the mouthwashes at significantly various degrees depending on concentration and type, except F1 which showed no activity. The zero antimicrobial profile of F1 was expected since it is a placebo product without extract. For the formulated mouthwashes, C. albicans was the most sensitive followed by $S$. aureus and $S$. mutans. These activities occur in a concentration-dependent manner with a significant increase in activity, with an increase in the concentration of the extract in the formulations. Mouthwashes containing the extract had significant activity on $C$. albicans $(P<0.0001)$ at all concentrations employed in this study when compared to the commercial brands. At high concentrations of the extract in formulations F4 $(0.3 \% \mathrm{w} / \mathrm{v})$ and F5 $(0.5 \% \mathrm{w} / \mathrm{v})$, the antibacterial activity of these formulations were significantly higher against $S$. mutans and $S$. aureus $(P<0.0001)$ when compared with the commercial brands, except F6, which had a significantly higher activity against $\mathrm{S}$. aureus than formulation F4 $(0.3 \% \mathrm{w} / \mathrm{v})$. However, at low concentrations of the extract in formulations F2 $(0.1 \% \mathrm{w} / \mathrm{v})$ and F3 $(0.2 \% \mathrm{w} / \mathrm{v})$, the antibacterial activity of these formulations were significantly lower against S. mutans and S. aureus $(\mathrm{P}<0.0001)$ when compared with the commercial brands.

The rating of the physical characteristics of the mouthwashes from the assessment of panelists indicated generally that more than $50 \%$ of the panelists perceived all the mouthwashes as being good in appearance, colour, odour and smoothness, without a gritty taste. Generally, more than 50\% of the panelists perceived the formulated mouthwashes to have a poor flavour and taste, unlike the commercial brands, which over $70 \%$ of the panelist perceived as having a good flavour and taste. More than $70 \%$ of the panelist accepted the commercial brands while less than $50 \%$ of panelists generally rejected the formulated mouthwashes. The rejection of the formulated mouthwashes was based on its palatability in which the flavour and sweetener in the formulation was a determining factor. Sweetener was not included in the formulated mouthwash, hence its high rejection rate. However, the commercial brand mouthwashes gained a high rate of acceptance due to the presence of sweeteners: sodium saccharin and sorbitol. The acceptability of the formulated mouthwashes can be improved upon by enhancing its palatability with the inclusion of a suitable sweetener.

The physical characteristics (appearance, colour, taste, odour and flavour) of the mouthwash were stable at the selected temperature for 12 weeks. There was a slight reduction in the antimicrobial activity of the mouthwash against the test microorganisms with an increase in the storage temperature and time duration. However, statistical analysis revealed no significant difference in antimicrobial activity. So, it can be said that the antimicrobial stability of the mouthwash was maintained at the selected temperature for 12 weeks. This finding is an indication that the mouthwash can be stored on shelves at room temperatures without becoming compromised.

Further research is necessary to isolate and evaluate the compound in the plant responsible for the antimicrobial activity in vivo. Also, toxicological evaluation of the formulated mouthwash is necessary to ascertain its safety. 


\section{CONCLUSION}

The test microorganisms were sensitive to the mouthwashes but at various degrees depending on the concentration of the extract. The formulated mouthwashes showed more remarkable activity than the commercial brands. The formulated mouthwashes were stable in physical attributes and activity but were poor in acceptability and need to be improved to be considered for commercial production. This study concludes that the use of Distemonanthus benthamianus chewing stick extract mouthwash would be an effective, cheap and safe means to prevent dental caries and oro-dental infections compared to the commercial brand mouthwashes.

Acknowledgement: The authors are grateful to Mr king, Miss Tawa Lawal and Mrs Olupe, the laboratory technologists in the Faculty of Pharmacy, Olabisi Onabanjo University, Ago Iwoye, Nigeria for providing laboratory assistance.

Peer-review: Externally peer-reviewed.

Author contributions: Conception/Design of Study- M.N.F., O.A.A., C.O.B., M.N.A.; Data Acquisition- O.A.A., O.B.B., M.N.A., F.O.O.; Data Analysis/Interpretation- M.N.F., O.A.A., C.O.B., M.N.A., F.O.O.; Drafting Manuscript- O.A.A., O.B.B., M.N.A.; Critical Revision of Manuscript- M.N.F., O.A.A., C.O.B., F.O.O.; Final Approval and Accountability- M.N.F., O.A.A., C.O.B., O.B.B., M.N.A., F.O.A.

Conflict of Interest: The authors have no conflict of interest to declare.

Financial Disclosure: Authors declared no financial support.

\section{REFERENCES}

- $\quad$ Adeleye, O.A., Babalola, C.O., Femi-Oyewo, M.N., \& Balogun, G.Y. (2019). Antimicrobial activity and stability of Andrographis paniculata cream containing shea butter. Nigerian Journal of Pharmaceutical Research, 15, 9-18.

- $\quad$ Adeniyi, B.A., Obasi, O.J., \& Lawal, T. (2011). In vitro antifungal activity of Distemonanthus benthamianus stem. International Journal of Pharmacy and Pharmaceutical Sciences, 3, 52-56.

- $\quad$ Adeniyi, C.B., \& Odumosu, B.T. (2012). Antibacterial and antifungal properties of Distemonanthus benthamianus (Fabaceae) crude extract. Global Journal of Pharmaceutical Research, 1, 567-574.

- $\quad$ Adeniyi, T.A., Adeonipekun, P.A „ \& Omotayo, E.A. (2014). Investigating the phytochemicals and antimicrobial properties of three sedge (Cyperaceae) species. Notulae Scientia Biologicae, 6, 276-281.

- $\quad$ Aiyegoro, O.A., Akinpelu, D.A., Afolayan, A.J., \& Okoh, A.I. (2008). Antibacterial activities of crude stem bark extracts of Distemonanthus benthamianus. Journal of Biological Sciences, 8, 356-361.

- Almekhlafi, S., Thabit, A.M., Alwossabi, M.I., Awadth, N., Thabe, A.M., \& Algaadari, Z. (2014). Antimicrobial activity of Yemeni myrrh mouthwash. Journal of Chemical and Pharmaceutical Research, 6, 1006-1013.

- $\quad$ Asamoah, A., Frimpong-Mensah, K., \& Antwi-Boasiako, C. (2014). Efficacy of Erythropleum suaveolens (potrodom) and Distemonanthus benthamianus (bonsamdua) water extractives on the durability of five Ghanaian less used timber species. Journal of Indian Academy of Wood Science, 11, 72-81.

- $\quad$ Aworinde, D.O., Erinoso, S.M., \& IbukunOluwa, M.R. (2016). Mineral compositions, phytochemical constituents and in vitro antimicrobial screening of some chewing sticks from Ibadan, Nigeria. Journal of Applied Bioscience, 101, 9589-9597.
Baliga, S., Muglikar, S., Kale, R. (2013). Salivary pH: A diagnostic biomarker. Journal of Indian Society of Periodontology, 17, 461-465. Belardinelli, P.A., Morelatto, R.A., Benavidez, T.E., Baruzzi, A.M., \& López de Blanc, S.A. (2014). Effect of two mouthwashes on salivary $\mathrm{pH}$. Acta Odontology Latinoamericana, 27, 66-71.

- $\quad$ Dabholkar, C.S., Shah, M., Kathariya, R., Bajaj, M., \& Doshi, Y. (2016). Comparative evaluation of antimicrobial activity of pomegranate-containing mouthwash against oral-biofilm forming microorganisms. Advances in Human Biology, 6, 99-103.

- $\quad$ Dave, P.H., Gurunathan, D., Vasantharajan, M.S. (2018). Comparison of pH levels of the saliva before and after the consumption of cough syrups in children. Biomedical and Pharmacology Journal, 11, 1443-1448.

- Hood, J.R., Wilkinson, J.M., \& Cavanagh, H.M.A. (2003). Evaluation of common antibacterial screening methods utilized in essential oil research. Journal of Essential Oil Research, 15, 428-433.

Khirtika, S.G., Ramesh, S., \& Muralidharan, N.P. (2017). Comparative evaluation of antimicrobial efficacy of $0.2 \%$ Chlorhexidine, $2 \%$ iodine and homemade mouthrinse as an anti-caries agent. Journal of Pharmaceutical Science Research, 9, 2114-2116.

- $\quad$ Kunte, S., Kadam, N., Patel, A., Shah, P., Lodaya, R., \& Lakde, L. (2018). Comparative evaluation of antimicrobial properties of pomegranate peel extract against Streptococcus mutans and Lactobacillus. International Dental and Medical Journal of Advanced Research. 4, 1-6. - Malik, A.S., Shaukat, M.S., Qureshi, A.A., \& Abdur, R. (2014). Comparative effectiveness of chewing stick and toothbrush: a randomized clinical trial. North American Journal of Medical Sciences, 6, 333-337.

- Masadeh, M.M., Gharaibeh, S.F., Alzoubi, K.H., Al-Azzam, S.I., \& Obeidat, W.M. (2013). Antimicrobial activity of common mouthwash solutions on multidrug-resistance bacterial biofilms. Journal of Clinical Medical Research, 5, 389-394.

- Mebude, O.O„ Adeniyi, B.A., \& Lawal, T.O. (2017). In vitro antimicrobial activities of ethanol extract of Distemonanthus benthamianus (Aayan) Baillon (Fabaceae) on Streptococcus mutans. Journal of Advances in Medicine and Medical Research, 22, 1-8.

- $\quad$ Obiang, C.S., Misso, R.L., Atome, G.R., Ondo, J.P., Engonga, L.C., \& Emvo, E.N. (2019). Phytochemical analyses, antimicrobial and antioxidant activities of stem bark extracts of Distemonanthus benthamianus H. Baill. and fruit extracts of Solanum torvum Sw. from Gabon. Asian Pacific Journal of Tropical Biomedicine, 9, 209-216.

- Parkar, S.M., Thakkar, P., \& Shah, K. (2013). Antimicrobial activity of four commercially available mouthwashes against streptococcus Mutans: An in vitro study. Universal Research Journal of Dentistry, 3, 108-112.

- Saha, J.B., Pétrissans, A., Molina, S., Ndikontar, M.K., Mounguengui, S., Dumarçay, S., \& Gérardin, P. (2014). Study of the feasibility of a natural dye on cellulosic textile supports by red padouk (Pterocarpus soyauxii) and yellow movingui (Distemonanthus benthamianus) extracts. Industrial Crops and Products, 60, 291-297.

- $\quad$ Shittu, O.A., Aliyu, A., David, M.S., Njinga, N.S., \& Ishaq, H.I. (2019). Potential antibacterial activity of two important local chewing sticks "Fagara zanthoxyloides and Distemonanthus benthamianus" along with antioxidant capacities. Dhaka University Journal of Pharmaceutical Sciences, 18, 223-232.

- Takahashi, N. (2005). Microbial ecosystem in the oral cavity: Metabolic diversity in an ecological niche and its relationship with oral diseases. International Congress Series, 1284, 103-112.

- Trease, A., \& Evans, W.C. (1989). Pharmacognosy. 13th (ed). London: Balliene Tindiall. Pp. 345-6, 535-6, 772-3.

Van Zyk, A.W., \& Van Heerdem, W.F. (2010). Mouthwash: A review for South African health care workers. South African family practice. Research Journal of Pharmaceutical, Biological and Chemical Sciences, 5, 121-127.

- Yadav, R., \& Yadav, S.K. (2013). Dental disease and its cure: A review. Asian Journal of Pharmaceutical and Clinical Research, 6, 16-20.

- $\quad$ Zhao, D., Tsoi, J.K., Wong, H.M., Chu, C.H., \& Matinlinna, J.P. (2017). Pediatric over-the-counter (OTC) oral liquids can soften and erode enamel. Dentistry Journal, 5, 17-24. 